OPEN ACCESS

Edited by:

Chaudhery Mustansar Hussain, New Jersey Institute of Technology,

United States

Reviewed by:

Wei-Lung Tseng

National Sun Yat-sen

University, Taiwan

Martina Catani,

University of Ferrara, Italy

*Correspondence: Ingrid Hagarová

ingrid.hagarova@uniba.sk

Specialty section:

This article was submitted to

Analytical Chemistry,

a section of the journal

Frontiers in Chemistry

Received: 26 February 2021

Accepted: 12 April 2021

Published: 04 May 2021

Citation:

Hagarová I and Nemček L (2021) Application of Metallic Nanoparticles

and Their Hybrids as Innovative

Sorbents for Separation and

Pre-concentration of Trace Elements

by Dispersive Micro-Solid Phase

Extraction: A Minireview.

Front. Chem. 9:672755.

doi: 10.3389/fchem.2021.672755

\section{Application of Metallic Nanoparticles and Their Hybrids as Innovative Sorbents for Separation and Pre-concentration of Trace Elements by Dispersive Micro-Solid Phase Extraction: A Minireview}

Ingrid Hagarová* and Lucia Nemček

Institute of Laboratory Research on Geomaterials, Faculty of Natural Sciences, Comenius University in Bratislava, Bratislava, Slovakia

It is indisputable that separation techniques have found their rightful place in current analytical chemistry, considering the growing complexity of analyzed samples and (ultra)trace concentration levels of many studied analytes. Among separation techniques, extraction is one of the most popular ones due to its efficiency, simplicity, low cost and short processing times. Nonetheless, research interests are directed toward the enhancement of performance of these procedures in terms of selectivity. Dispersive solid phase extraction (DSPE) represents a novel alternative to conventional solid phase extraction (SPE) which not only delivers environment-friendly extraction with less solvent consumption, but also significantly improves analytical figures of merit. A miniaturized modification of DSPE, known as dispersive micro-solid phase extraction (DMSPE), is one of the most recent trends and can be applied for the extraction of wide variety of analytes from various liquid matrices. While DSPE procedures generally use sorbents of different origin and sizes, in DMSPE predominantly nanostructured materials are required. The aim of this paper is to provide an overview of recently published original papers on DMSPE procedures in which metallic nanoparticles and hybrid materials containing metallic particles along with other (often carbon-based) constituent(s) at the nanometer level have been utilized for separation and pre-concentration of (ultra)trace elements in liquid samples. The studies included in this review emphasize the great analytical potential of procedures producing reliable results in the analysis of complex liquid matrices, where the detection of target analyte is often complicated by the presence of interfering substances.

Keywords: metallic nanoparticles, carbon-based nanomaterials, dispersive micro-solid phase extraction, aqueous samples, ultratrace elements 


\section{INTRODUCTION}

The separation techniques have rapidly gained popularity in recent years, as they represent a powerful tool to deal with the complexity of analyzed samples and (ultra)trace concentrations of studied analytes. Among separation techniques, the extraction procedures are particularly efficient in sample clean-up and analyte enrichment. Among these procedures, solid phase extraction (SPE), has become the most extensively used method in (ultra)trace analysis owing to many advantages over traditional separation techniques such as high extraction recoveries and high enrichment factors. In the last years, numerous modifications of this technique have been described in terms of different arrangements. Dispersive solid phase extraction (DSPE) as a novel alternative to conventional SPE is based on the dispersion of a solid sorbent in a liquid sample with no need for SPE column, extraction disc or cartridge. The advanced functional properties of the sorbent allow for direct interaction with the target analytes which favors the kinetics of the sorption and increases the efficiency of the extraction process. Another positive aspect related to this separation technique revolves around development and application of new and advanced sorption materials. The introduction of advanced sorbents favors the enhancement of selectivity toward the target analytes, higher sorption capacity and improvement of physicochemical and/or mechanical stability. The consumption of small amounts of sorbent (in the low milligram range) has led to a modification of the dispersive extraction, so-called dispersive micro-solid phase extraction (DMSPE). The DMSPE principle is similar to that of DSPE. After trapping the analyte on a sorbent dispersed in a liquid sample, the sorbent is usually isolated by centrifugation. The target analytes are eventually desorbed with a small amount of solvent appropriate for instrumental analysis. The DMSPE procedure is illustrated in Figure 1.

In DSPE procedures, reliable dispersion of the sorbent plays a crucial role. Dispersibility must be maintained during the whole extraction process, including the part where the analyte sorbs onto the sorbent and desorbs back into solution. For this reason, the dispersion needs to be assisted by the use of an external energy source (e.g., mechanical stirring) or chemicals. The different approaches allowing for the dispersion of a solid sorbent in DMSPE were compared by Chisvert et al. (2019).

The selection of a proper sorbent is an essential step toward development of reliable DMSPE procedure. While micro-sized materials of solid nature were commonly used at a time of early design stages of DMSPE, solid materials of a nanosize are preferably being used lately. Owing to their extremely small size and large surface area, they offer unique physical and chemical properties that are often very different from the properties of the same materials assembled at the micro- or macroscopic scale. In this regard, different nanoparticles of metallic nature have been tested as a new sorbent material for the separation and pre-concentration of organic and inorganic analytes in a number of environmental, biological, pharmaceutical, and food samples. The limits of detection (LODs) for particular analytes and the detection methods have been experimentally determined and are reported in Table 1.
Nanomaterials can be classified into different groups on the basis of their nature, composition, shapes, sizes, etc. In regard to their nature, nanomaterials are available in both natural and synthetic variations. In terms of their chemical composition, two main classes can be distinguished, inorganic (e.g., compounds containing metal or metal oxide) and organic (e.g., carbonaceous, polymeric materials). In recent years, a growing interest has been directed toward the use of hybrid organic-inorganic nanomaterials in which the functionality of organic compounds is combined with the stability of inorganic materials (Pyrzynska, 2020). The rising demand for hybrid multifunctional nanomaterials has stemmed from the need to enhance extraction efficiency. Whereas, mono-functional nanomaterials can offer only one type of interaction, the hybrid nanomaterials can improve extraction efficiency due to the synergistic effect resulting from interactions between different materials.

In terms of their structure, three main groups can be distinguished: nanoparticles (NPs), nanolayers (NLs), and nanotubes (NTs). Nanoparticles containing pure metals or their compounds in a core or shell are denoted as metallic. The class covers a variety of materials including metals (e.g., $\mathrm{Au}, \mathrm{Ag}, \mathrm{Cu}$, $\mathrm{Fe}$ ), metal oxides (e.g., $\mathrm{TiO}_{2}, \mathrm{ZrO}_{2}, \mathrm{ZnO}, \mathrm{CuO}, \mathrm{Al}_{2} \mathrm{O}_{3}, \mathrm{Fe}_{\mathrm{x}} \mathrm{O}_{\mathrm{y}}$ ), and other metal-containing NPs (e.g., CdSe/ZnS quantum dots). While there are also other materials used for nanolayers and nanotubes, carbon is still by far the best choice and therefore most research has been aimed toward the carbon ones. Metallic nanoparticles and carbonaceous nanomaterials have found their way into DMSPE procedures developed for efficient detection of various analytes, both organic and inorganic.

This minireview presents current DMSPE procedures for separation and/or pre-concentration of (ultra)trace elements which involve the use of metallic nanoparticles and hybrid materials consisting of metallic particles immobilized on surface of some advanced (mostly carbon-based) materials at the nano-scale.

\section{METALLIC NANOPARTICLES AND HYBRID NANOMATERIALS CONTAINING METALLIC NANOPARTICLES AS SORBENTS FOR EFFICIENT TRACE ELEMENT SEPARATION AND PRE-CONCENTRATION BY DMSPE}

Silver nanoparticles (AgNPs) and gold nanoparticles (AuNPs) have positioned themselves as one of the leading materials that are extensively used in various applications, including extraction procedures. Metal oxide nanoparticles, such as $\mathrm{TiO}_{2}, \mathrm{ZrO}_{2}, \mathrm{ZnO}$, and $\mathrm{Al}_{2} \mathrm{O}_{3}$, belong to the family of amphoteric oxides and their application in extraction procedures allows for the extraction of both cations and anions (after the optimization of experimental conditions). Nanosized metal oxides act as ion-exchangers with large specific surface area and mesoporous structure, and are perceived as promising candidates for the sorption of various elements in aqueous media. Their thermal stability, good mechanical performance, and radiation resistance are definitely among the most significant benefits. However, particle size 


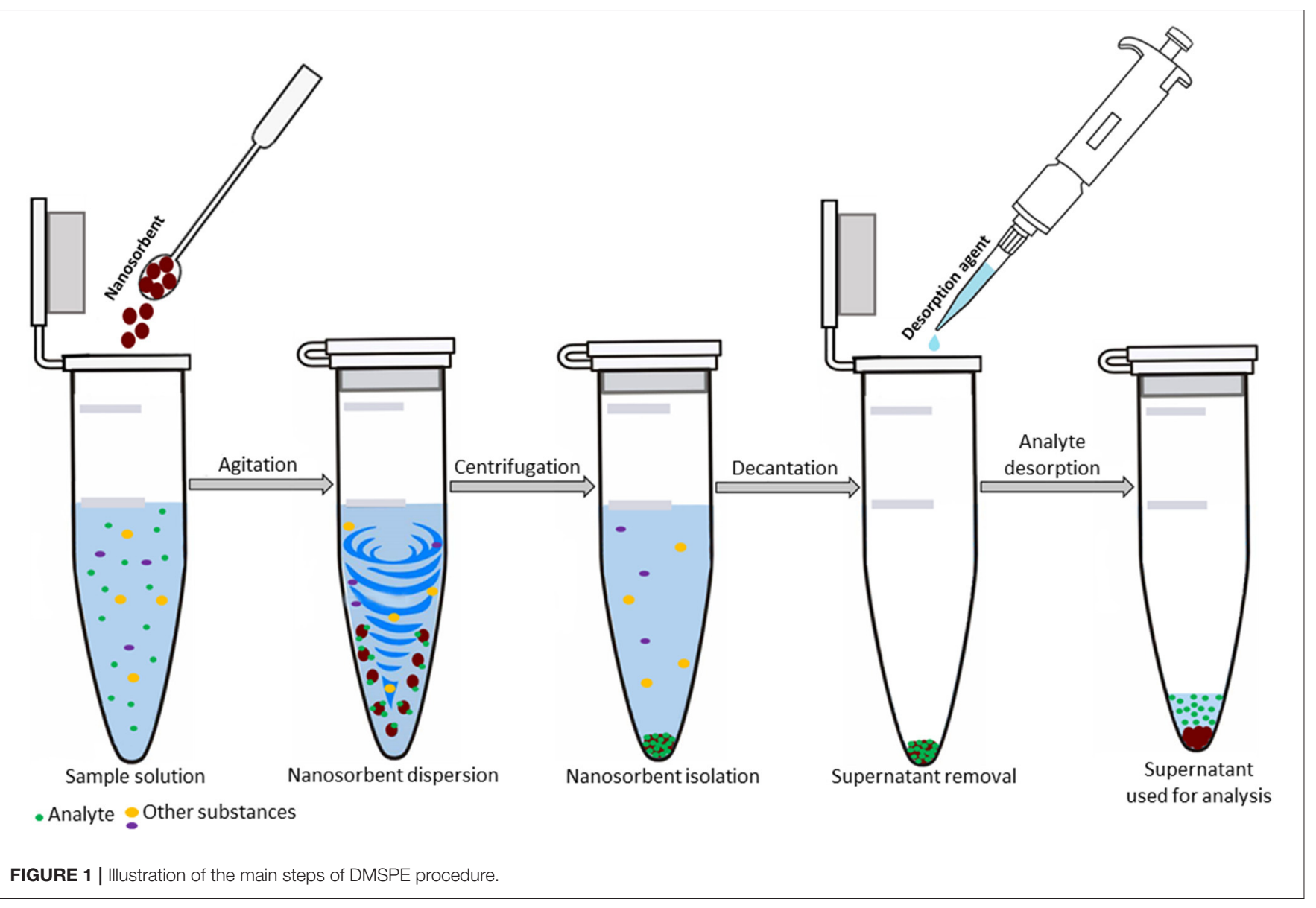

reduction is accompanied by changes in surface energy and affects the stability of the powder. With size reduced from micrometer to nanometer level, metal oxides have a tendency to form agglomerates due to interparticle forces, such as Van der Waals and electrostatic forces. Therefore, in nanoform they are relatively rarely used individually as adsorbents in extraction experiments (Karadjova et al., 2016). Combination of nanooxides with a carbonaceous support can eliminate this complication and give rise to a hybrid material with superior properties. It has been recognized that graphitization heat treatment of carbon fibers opens up new possibilities for the preparation of novel materials with increasing relevance in commercial as well as small-scale laboratory, industrial and research applications.

Carbon-based nanomaterials with a set of unique properties include graphite, diamond, glassy carbon, graphene, amorphous powders, carbon fibrous materials, carbon nanofibers (CNFs), and carbon nanotubes (CNTs) (Navrotskaya et al., 2020). This section is intended as a brief review of some representative studies on metallic nanoparticles combined with carbon-based nanostructures for the effective separation and pre-concentration of trace elements in aqueous media. By performing DSMPE measurements on presented types of nanomaterials, reliable results were achieved.

\section{Noble Metal Nanoparticles}

Metallic nanoparticles containing valuable metals such as silver and gold exhibit unique optical, physical, chemical, and biological properties that are exploited in a wide range of applications (Hagarová, 2020). Their strong affinity for inorganic and organic mercury species can be utilized in extraction procedures for mercury binding. However, metallic nanoparticles containing noble metals can also be applied for the separation of other heavy metals (Li et al., 2020), organic species (pyrene, olefins, methylene blue) and gaseous species $\left(\mathrm{NO}, \mathrm{SO}_{2}\right)$ (Dastafkan et al., 2015).

Commercially available silver nanoparticles (AgNPs) have been lately used as solid sorbent in an ultrasound-assisted DMSPE (UA-DMSPE) procedure for separation and preconcentration of $\mathrm{Hg}^{2+}$ ions in real spring water, tap water and ground water samples (Krawczyk and Stanisz, 2015). In this procedure, the adsorption of mercury on AgNPs is followed by separation of the liquid phase from the solid phase. Liquid phase is then removed and solid phase is immediately dissolved in $7 \mathrm{M} \mathrm{HNO}_{3}$. The mercury content is quantified by highresolution continuum source electrothermal atomic absorption spectrometry (HR-CS ETAAS). The limit of detection (LOD) of this method has been calculated as $5 \mathrm{ng} / \mathrm{L}$ which demonstrates a 
TABLE 1 | Summary table of the data obtained from experiments using metallic nanoparticles as sorbents in DMSPE procedures.

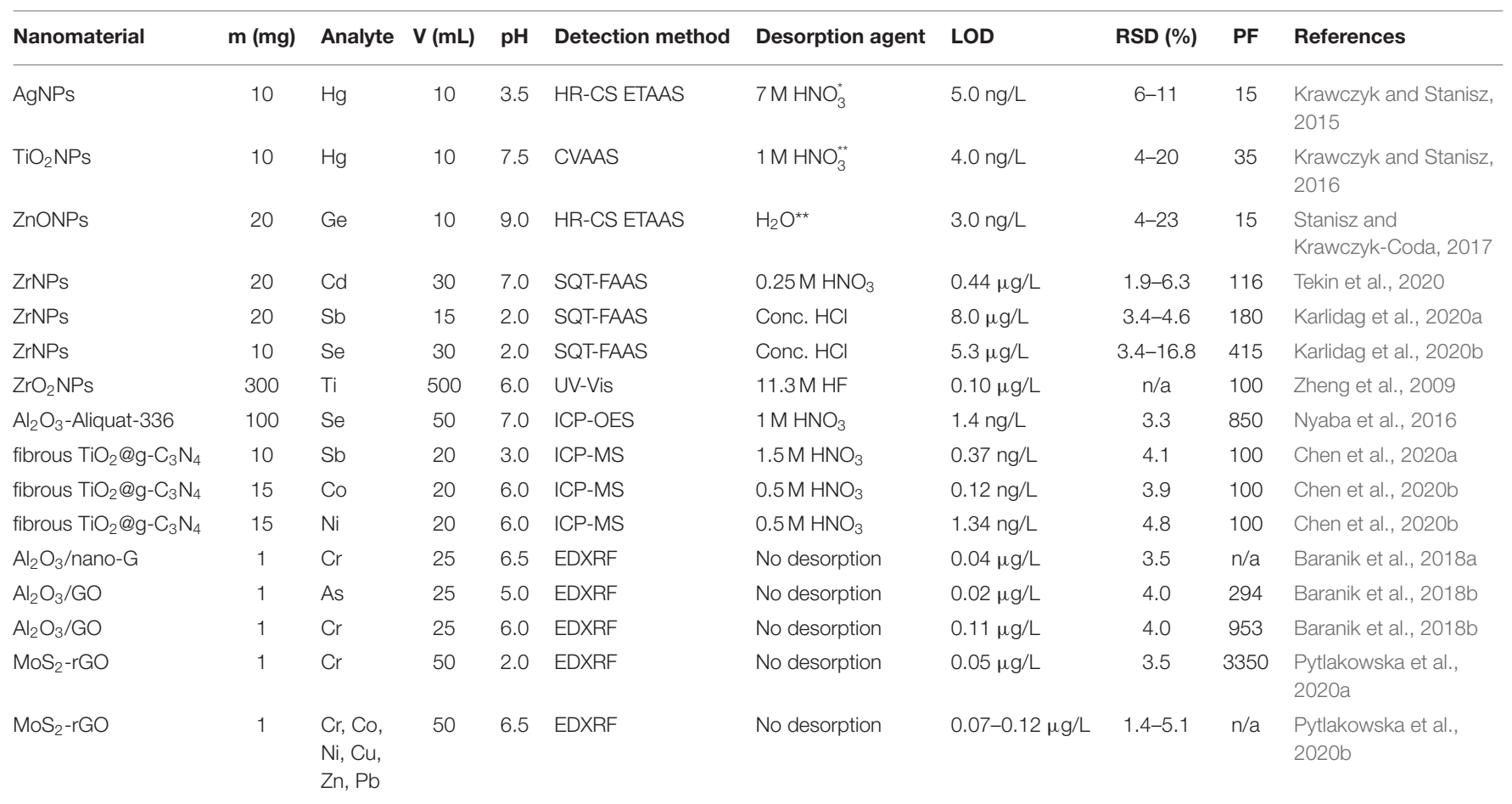

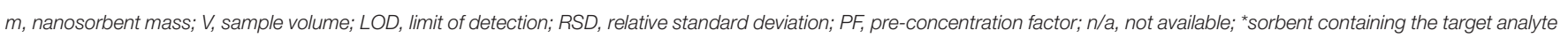
is dissolved and the concentration of the analyte in solution is determined; **the analyte is captured on a solid support which is in the form of a slurry.

great potential of the method in an ultratrace analysis of mercury ions in natural waters.

In a multistep process, Yordanova et al. (2014) prepared AgNPs supported on the surface of $\mathrm{NH}_{2}$-functionalized silica submicrospheres ( $\mathrm{SiO}_{2} / \mathrm{AgNPs}$ ) to be used as a sorbent for separation and pre-concentration of inorganic mercury in surface water samples during extraction procedure. This novel nanocomposite adsorbent was synthesized by a completely green procedure and was rigorously characterized by transmission electron microscopy (TEM), UV-Vis spectroscopy, X-ray diffraction (XRD), and atomic force microscopy (AFM).

Besides silver, utilization of gold in a form of nano-sized material in analytical chemistry has become a topic of interest during the last decades. The continued popularity of AuNPs can be attributed to their size- and shape- dependent optical and electrical properties and high electrocatalytic activity. Moreover, the surface chemistry of AuNPs is versatile, allowing the linking of various biofunctional groups (e.g., amphiphilic polymers, silanols, sugars, nucleic acids, proteins) through strong $\mathrm{Au}-$ $\mathrm{S}$ or $\mathrm{Au}-\mathrm{N}$ bonding, or through physical adsorption (Lin et al., 2011). Such types of biomolecules can be adsorbed spontaneously onto gold surfaces generating well-organized, selfassembled monolayers (Khajeh et al., 2013), which favors these nanoparticles for application in procedures designed particularly for organic compounds separation.

Following the earlier work of Turkevich and Frens, Kiran (2015) synthesized AuNPs capped with 2-mercapto succinic acid in order to separate mercury from environmental water samples, vegetable, and crop samples collected near industrial areas. Nanoparticle structure and morphology was characterized by high-resolution transmission electron microscopy (HR-TEM) and scanning electron microscopy (SEM). The method was successfully applied to detect mercury up to ppb levels.

Palladium is considered the most valuable of the four major precious metals with extraordinary catalytic, powerful mechanical, and electroanalytical properties. Palladium nanoparticles (PdNPs) have been developed as self-therapeutics with proven anti-bacterial and cytotoxic pharmacological activity (Yaqoob et al., 2020). PdNPs have been applied as coprecipitation carriers for pre-concentration of $\mathrm{Cu}, \mathrm{Pb}$, and $\mathrm{Cd}$ in seawater and synthetic water samples prior to their measurement by atomic absorption spectrometry (AAS) (Zhuang et al., 1996). PdNPs have been found very useful in speciation studies conducted to determine $\mathrm{Cr}$ (VI) and $\mathrm{Cr}$ (III) in soil and aqueous media (Omole et al., 2007), and As(III) and As(V) in environmental water samples (Sounderajan et al., 2009).

The adsorption capacity of PdNPs as a DSPE sorbent for the separation and pre-concentration of selenium species in ground water has been evaluated by Kumar et al. (2015). The authors used sodium borohydrate for the reduction of $\operatorname{Pd}(\mathrm{II})$ to $\mathrm{Pd}(0)$ to obtain PdNPs. The same reducing agent was employed for the reduction of $\mathrm{Se}(\mathrm{IV})$ to $\mathrm{Se}(0)$. The reduced elemental selenium was then adsorbed on PdNPs surface. The PdNPs with adsorbed selenium were collected and dissolved in a minimum amount of nitric acid and the extracted selenium was quantified by electrothermal atomic absorption spectrometry (ETAAS). The 
adsorption capacity of PdNPs for $\mathrm{Se}(0)$ was $28 \mathrm{mg} / \mathrm{g}$ and the recoveries for $\mathrm{Se}(\mathrm{IV})$ and $\mathrm{Se}(\mathrm{VI})$ were in the range of $97-102 \%$.

\section{Zirconium and Zirconium Dioxide Nanoparticles}

Zirconium is a transition metal with extreme resistance to oxidation and corrosion which makes it ideal as an alloying agent choice for materials that are frequently exposed to corrosive environments (such as high temperatures, water, steam, acids, organic solvents, salts, etc.). Besides application of this metal in processes encountered in chemical engineering, zirconium and its compounds have found diverse uses in modern analytical chemistry as summarized by Pechishcheva et al. (2018). Very recently, the first work on application of zirconium nanoparticles (ZrNPs) in extraction procedures has been conducted.

Tekin et al. (2020) established a novel, green, highly accurate, and precise ZrNPs-based solid phase extraction strategy for separation and pre-concentration of trace cadmium prior to its quantification by slotted quartz tube-flame atomic absorption (SQT-FAAS). ZrNPs proved to be an effective adsorbent for the removal of Cd from water, the recovery rates of $96-100 \%$ were achieved.

ZrNPs have also been a choice of Karlidag and his co-workers who used it as sorbent material for the adsorption of antimony (Karlidag et al., 2020a) and selenium (Karlidag et al., 2020b) from tea samples by vortex assisted ligandless dispersive solid phase extraction (VA-LDSPE) and dispersive solid phase extraction (DSPE) method. Analyte quantification was performed by SQTFAAS. Using Zr-NPs-VA-LDSPE-SQT-FAAS method, the analyte was detectable at concentrations 180 -fold lower than those detected by conventional method. The obtained recovery values ranged between 93 and $102 \%$ for Sb and 92 and $101 \%$ for Se.

Zirconium dioxide $\left(\mathrm{ZrO}_{2}\right)$, also known as zirconia, is a widely used inorganic material with exceptional biocompatibility, high mechanical and thermal stability, wear and corrosion resistance, chemical inertness and low systemic toxicity. However, in comparison with other metallic oxides used in extraction procedures for trace elements, it is considered less frequently used one. Yet, it has been successfully applied for the preconcentration of Ti(IV) in water samples by Zheng et al. (2009) in a batch extraction procedure. Zirconium dioxide was in the form of ultrafine amorphous spherical powder prepared by precipitation in micro-droplets which act as nanoreactors in the microemulsion system composed of cyclohexane/water/TritonX100/hexyl alcohol. The powder so obtained had particles substantially uniform in diameter and with low-aggregation behavior (Ma et al., 2004). The concentration of $\mathrm{Ti}(\mathrm{IV})$ was determined using a UV-1200 PC spectrophotometer. After optimization of experimental conditions, the authors achieved a limit of detection of $0.1 \mu \mathrm{g} / \mathrm{L}$.

\section{Titanium Dioxide Nanoparticles}

Titanium dioxide nanoparticles $\left(\mathrm{TiO}_{2} \mathrm{NPs}\right)$ have already shown outstanding performances in photoelectrochemical and photocatalytic processes. They have also found their application in extraction procedures as solid sorbents, owing to their optimal physicochemical properties (e.g., high thermal and chemical stability), high specific surface area, high adsorption capacity, low cost, and low toxicity (Krawczyk and Stanisz, 2016). $\mathrm{TiO}_{2} \mathrm{NPs}$ have been used for separation and pre-concentration of various trace elements in extraction procedures (Xu et al., 2018).

The method combining ultrasound-assisted DMSPE (UADMSPE) with cold vapor atomic absorption spectrometry (CVAAS), where $\mathrm{TiO}_{2} \mathrm{NPs}$ were successfully used for separation and pre-concentration of total mercury and mercury species $\left(\mathrm{Hg}^{2+}\right.$ and $\left.\mathrm{CH}_{3} \mathrm{Hg}^{+}\right)$in biological, geological, and water samples, has been presented by Krawczyk and Stanisz (2016). After extraction, a sorbent with entrapped analyte was separated from the bulk solution and mixed with $1 \mathrm{M} \mathrm{HNO}_{3}$ to prepare a slurry that was then measured for mercury. However, it is known that detection limits that can be achieved using CVAAS after preconcentration on $\mathrm{TiO}_{2} \mathrm{NPs}$ are better than those obtained with conventional CVAAS.

In a study by Chen et al. (2020a), the fibrous $\mathrm{TiO}_{2} @ g-\mathrm{C}_{3} \mathrm{~N}_{4}$ nanocomposites (FTGCNCs) were tested as a new adsorbent for separation of various antimony species [ $\mathrm{Sb}(\mathrm{III}), \mathrm{Sb}(\mathrm{V})$, residual, digestible, and total $\mathrm{Sb}$ ] in a cow milk by DMSPE prior to inductively coupled plasma mass spectrometry (ICPMS) analysis. The results showed that $\mathrm{Sb}(\mathrm{III})$ was quantitatively adsorbed on FTGCNCs in the $\mathrm{pH}$ range of 2-4, while $\mathrm{Sb}(\mathrm{V})$ remained in an aqueous phase. Compared to other separation and detection methods, particularly solid-phase microextraction coupled to inductively coupled plasma mass spectrometry (SPME-ICP-MS), ion chromatography coupled to inductively coupled plasma mass spectrometry (IC-ICPMS), magnetic solid phase extraction coupled to inductively coupled plasma mass spectrometry (MSPE-ICP-MS), highperformance liquid chromatography coupled to inductively coupled plasma mass spectrometry (HPLC-ICP-MS), cloud point extraction combined with electrothermal vaporization inductively coupled plasma mass spectrometry (CPE-ETV-ICPMS) and hydride generation inductively coupled plasma mass spectrometry (HG-ICP-MS), this approach allows for more accurate determination of sample composition and results in a lower LOD $[0.37 \mathrm{pg} / \mathrm{mL}$ for $\mathrm{Sb}(\mathrm{III})]$ and higher enrichment factor (100).

The efficiency of FTGCNCs as sorbent material was supported in their following study (Chen et al., 2020b), where FTGCNCs were used for DMSPE of Co and Ni prior to their determination by ICP-MS. The apparent selectivity of this material for some metal ions can be attributed to a large number of $-\mathrm{NH}_{2},-\mathrm{NH}-$ and $=\mathrm{N}$ functional groups distributed on FTGCNCs' surface. For Co and Ni retention on FTGCNCs, the optimal pH ranges between 5 and 8 .

Although graphitic carbon nitride $\left(\mathrm{g}-\mathrm{C}_{3} \mathrm{~N}_{4}\right)$ shows great potential as a new sorbent in future sample pretreatment techniques, it has some issues from the DMSPE point of view. Pure g- $\mathrm{C}_{3} \mathrm{~N}_{4}$ easily aggregates which results in a decrease of its specific surface area (Sun et al., 2016). The weak polarity of g- $\mathrm{C}_{3} \mathrm{~N}_{4}$ causes its poor dispersion in water. Fortunately, these problems can be solved by the in-situ growth of g- $\mathrm{C}_{3} \mathrm{~N}_{4}$ on the surface of $\mathrm{TiO}_{2}$ nanofibers (TDNFs) to form the fibrous $\mathrm{TiO}_{2} @ g-\mathrm{C}_{3} \mathrm{~N}_{4}$ nanocomposites (FTGCNCs). 


\section{Zinc Oxide Nanoparticles}

The features such as large specific surface area, high porosity, low toxicity, and easy preparation have ensured great success of zinc oxide nanoparticles ( $\mathrm{ZnONPs}$ ) throughout the field of chemistry. In SPE procedures, ZnONPs have found application as effective nanosorbents. This material has been successfully used for efficient separation and pre-concentration of trace germanium in various food samples including tea leaves and mixed herbs by an ultrasound-assisted dispersive micro-solid phase extraction (UA-DMSPE) prior to its determination by highresolution continuum source electrothermal atomic absorption spectrometry (HR-CS ETAAS) (Stanisz and Krawczyk-Coda, 2017).

Zinc oxide is a unique material with versatile industrial and commercial applications. However, there is a constant race toward the performance enhancement. Doping is one of the methods commonly used for nanoparticle modification in order to enhance their electrical, optical, physical, biological, and chemical properties. Doping can increase the surface area, reduce the mass, and alter nanoparticle morphology resulting in optimized functional properties of nanomaterials (Khan et al., 2016). Although the methodology of the following work is based on thermodynamic and kinetic principles, the general steps followed in dispersive extraction (e.g., addition of $25 \mathrm{mg}$ of Cadoped $\mathrm{ZnONPs}$ to the metal ion solution) classify this procedure as DMSPE. Khan et al. (2016) developed simple, sensitive and innovative $\mathrm{Ca}$-doped $\mathrm{ZnONPs}$ extraction system for the recognition and elimination of $\mathrm{Pb}(\mathrm{II})$ ions in real water samples (drinking water, tap water, lake water, and seawater) based on a high selectivity of $\mathrm{Ca}$-doped $\mathrm{ZnONPs}$ for $\mathrm{Pb}(\mathrm{II})$. Although this sorbent material was also applied for the extraction of Cd(II), $\mathrm{Cu}(\mathrm{II}), \mathrm{Mn}(\mathrm{II}), \mathrm{Hg}(\mathrm{II}), \mathrm{Pd}(\mathrm{II}), \mathrm{La}(\mathrm{III})$, and Y(III), it was found to be highly selective for $\mathrm{Pb}(\mathrm{II})$. For this metal ion, the extraction efficiency of $94-99 \%$ was achieved. The adsorption process for $\mathrm{Pb}(\mathrm{II})$ was characterized as monolayer adsorption with the adsorption capacity of $84.66 \mathrm{mg} / \mathrm{g}$. Nanoparticle structure was studied by field emission scanning electron microscope (FESEM), $\mathrm{X}$-ray microanalysis (EDS), X-ray diffraction (XRD), X-ray Photoelectron (XPS), Fourier transform infrared spectroscopy (FTIR), and UV-Vis spectrophotometry.

\section{Aluminum Oxide Nanoparticles}

Aluminum oxide has become a typical sorbent material in SPE procedures. The high-performance of $\mathrm{Al}_{2} \mathrm{O}_{3}$ nanoparticles $\left(\mathrm{Al}_{2} \mathrm{O}_{3} \mathrm{NPs}\right)$ is attributed to a large specific surface area, high adsorption capacity, mechanical strength, high chemical activity, enhanced sorption kinetics, and low-temperature modification (Mohammadifar et al., 2015).

Hassanpoor et al. (2015) proposed a simple and efficient method for the extraction and speciation of trace quantities of arsenic in spiked real water, food and biological samples. For this purpose, $\mathrm{Al}_{2} \mathrm{O}_{3} \mathrm{NPs}$ were functionalized by a ligand containing donor atoms such as oxygen, nitrogen, and sulfur $\left[3,3^{\prime}\right.$-bis(3-triethoxysilylpropyl)-2,2' -dithioxo [5,5'] bithiazolidinylidene$4,4^{\prime}$-dione]. Desorption of the analyte was done by $1 \mathrm{M} \mathrm{HCl}$ and final measurements were performed by ETAAS. The adsorption capacity of the sorbent was tested in multiple cycles of adsorption and desorption. The obtained results showed that functionalized $\mathrm{Al}_{2} \mathrm{O}_{3} \mathrm{NPs}$ could be reused up to 70 times without any considerable loss in adsorption efficiency.

The different modification of $\mathrm{Al}_{2} \mathrm{O}_{3} \mathrm{NPs}$ used for selenium speciation in surface water samples by DMSPE procedure has been presented in a work published by Nyaba et al. (2016). In this study, $\mathrm{Al}_{2} \mathrm{O}_{3} \mathrm{NPs}$ were functionalized with quaternary ammonium salt (Aliquat336) and characterized by FTIR. Desorption of the analyte was done by diluted $\mathrm{HNO}_{3}$ and its quantification was performed by inductively coupled optical emission spectrometry (ICP-OES). The introduction of DMSPE prior to ICP-OES detection resulted in a significantly low LOD and LOQ (limit of quantification). The optimum $\mathrm{pH}$ for successful separation of inorganic Se species in sample solution was between 2 and 7 . The Se(IV) recovery was $>90 \%$, however, the recovery of $\mathrm{Se}(\mathrm{VI})$ was only near $5 \%$ over most of the $\mathrm{pH}$ range.

Baranik et al. (2018a,b) obtained novel aluminum oxide/graphene oxide and aluminum oxide/nano-graphite sorbents for $\mathrm{As}(\mathrm{V}), \mathrm{Cr}(\mathrm{III})$, and $\mathrm{Cr}(\mathrm{VI})$ pre-concentration in natural waters by means of (ultrasound-assisted-) DMSPE. Graphene oxide (GO) was synthesized by improved Hummers' method (Marcano et al., 2010) out of high purity graphite, sodium nitrate, sulphuric acid, potassium permanganate, and hydrogen peroxide. Alumina supported on graphene oxide $\left(\mathrm{Al}_{2} \mathrm{O}_{3} / \mathrm{GO}\right)$ nanocomposite was prepared by a simple sonothermo-chemical method involving dispersion of GO in a high purity water followed by addition of $\mathrm{Al}\left(\mathrm{NO}_{3}\right)_{3} \cdot 9 \mathrm{H}_{2} \mathrm{O}$. After an ultrasonic bath treatment followed by drying at $100^{\circ} \mathrm{C}$, the solid was heated at $500^{\circ} \mathrm{C}$ in a furnace to initiate the growth of $\mathrm{Al}_{2} \mathrm{O}_{3} \mathrm{NPs}$ on the $\mathrm{GO}$ surface. The aluminum oxide coated nano-graphite $\left(\mathrm{Al}_{2} \mathrm{O}_{3} /\right.$ nano-G) was synthesized out of $\mathrm{Al}\left(\mathrm{NO}_{3}\right)_{3} \cdot 9 \mathrm{H}_{2} \mathrm{O}$, Triton $\mathrm{X}-100$ and high purity graphene nanosheets in a sono-thermo-chemical process. Thus, prepared adsorbents were characterized by SEM, TEM, powder XRD, and Raman spectroscopy.

$\mathrm{Al}_{2} \mathrm{O}_{3}$ /nano- $\mathrm{G}$ has exhibited high selectivity for $\mathrm{Cr}$ (III) in the presence of $\mathrm{Cr}(\mathrm{VI}) . \mathrm{Al}_{2} \mathrm{O}_{3} / \mathrm{GO}$ has demonstrated selectivity toward arsenates in the presence of arsenites at $\mathrm{pH} 5$ and chromium(III) ions in the presence of chromate anions at $\mathrm{pH}$ 6. Under optimized conditions, $\mathrm{As}(\mathrm{V})$ and $\mathrm{Cr}(\mathrm{III})$ ions could be determined with very good precision (RSD 2.7-4\%), excellent LOD $(0.02 \mathrm{ng} / \mathrm{mL}$ As and $0.11 \mathrm{ng} / \mathrm{mL} \mathrm{Cr})$ and recovery rates $(92-$ $108 \%)$. Compared to $\mathrm{Al}_{2} \mathrm{O}_{3} / \mathrm{GO}$ nanocomposite, $\mathrm{Al}_{2} \mathrm{O}_{3}$ /nano-G has been characterized by better LOD values for $\mathrm{Cr}$ (III). Figure 2 illustrates the attraction/repulsion between positively charged metal ions and positively- and negatively-charged surface of a nanoparticle in a different $\mathrm{pH}$ environment.

\section{Molybdenum Disulfide Nanoparticles}

Pytlakowska et al. (2020a,b) ran experiments on two variants of graphene, graphene oxide (GO) and reduced graphene oxide (rGO), coupled with molybdenum disulfide $\left(\mathrm{MoS}_{2}\right)$ in order to investigate the potential of the hybrid material for the adsorption of metal ions. $\mathrm{MoS}_{2}$ was supported on GO by hydrothermal method. The resulting nanocomposite $\left(\mathrm{MoS}_{2}-\right.$ rGO) was characterized by XPS, SEM and TEM. The material was 


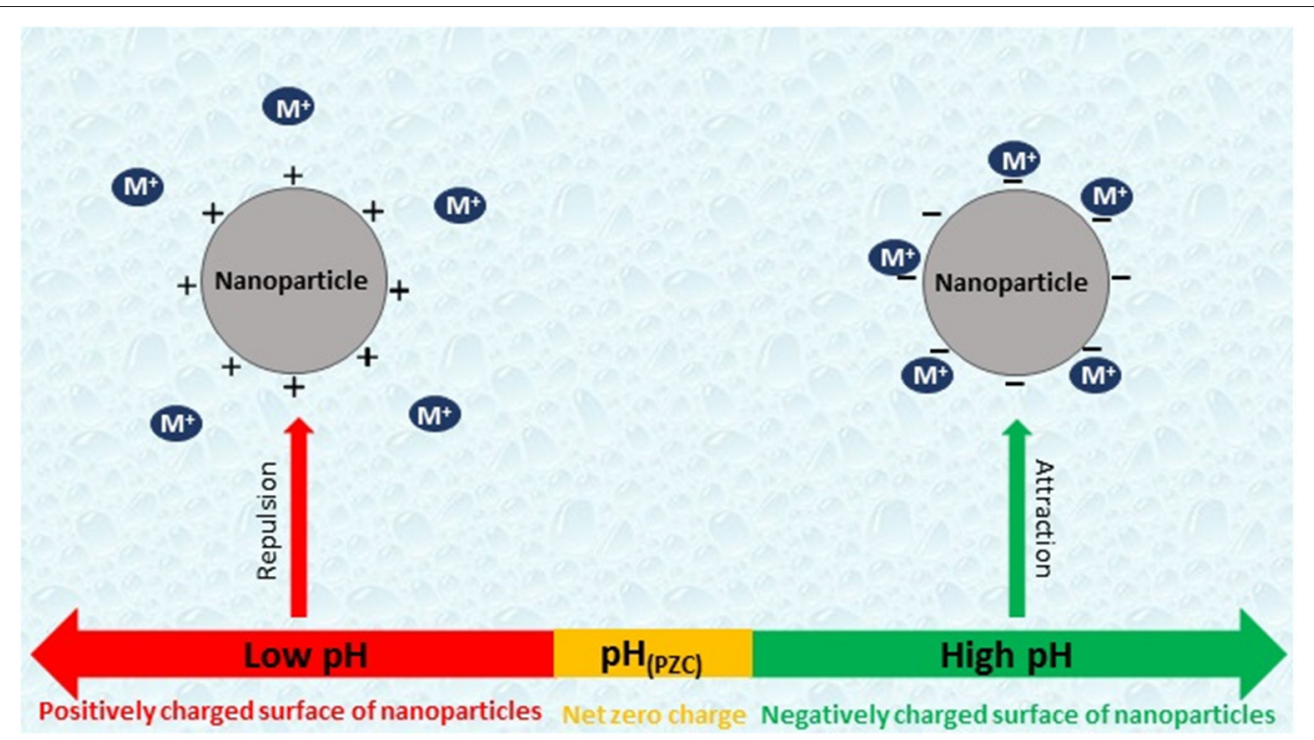

FIGURE 2 | The interaction between positively- and negatively-charged surface of a nanoparticle and positively charged metal ions ( $\mathrm{M}^{+}$) in a solution at pH values below and above the point of zero charge (PZC).

successfully applied for chromium speciation in real lake, spring and river water samples and artificial sea water by UA-DMSPE method. At $\mathrm{pH} 2, \mathrm{MoS}_{2}$-rGO showed a strong affinity for $\mathrm{Cr}$ (VI) leaving $\mathrm{Cr}$ (III) ions in an aqueous solution. The strong affinity of a target analyte toward $\mathrm{MoS}_{2}$-rGO NPs results from both electrostatic interaction and outsphere surface complexation. The adsorption capacity of $583.5 \mathrm{mg} / \mathrm{g}$ was nearly 6.5 times higher than that reported for untreated $\mathrm{MoS}_{2}$. The adsorption process was predominantly ruled by chemisorption.

Reduced graphene oxide (rGO) decorated with molybdenum disulfide $\left(\mathrm{MoS}_{2}\right)$ was synthesized by hydrothermal method and studied by different spectroscopic techniques, such as FTIR, Raman spectroscopy and XPS. The detailed high resolution images of the hybrid material were provided by SEM and TEM. $\mathrm{MoS}_{2}$-rGO has been evaluated as a solid nanoadsorbent for the pre-concentration of heavy metal ions in different water samples by DMSPE prior to energy dispersive X-ray fluorescence spectrometry (EDXRF) analysis. The maximum adsorption capacities were $\sim 1.5-5$-folds higher than those of unmodified GO; $q_{\max }$ were 235.1, 130.8, 279.3, 414.8, 483.7, $381.9 \mathrm{mg} / \mathrm{g}$ for $\mathrm{Cr}(\mathrm{III}), \mathrm{Co}(\mathrm{II}), \mathrm{Ni}(\mathrm{II}), \mathrm{Cu}(\mathrm{II}), \mathrm{Zn}(\mathrm{II})$, and $\mathrm{Pb}(\mathrm{II})$ ions, respectively. The introduction of ultrasound in adsorption process has resulted in excellent recovery rates (close to $100 \%$ after $10 \mathrm{~min}$ of sonication).

\section{SUMMARY}

Metallic nanoparticles (MNPs) have found varying applications on an industrial scale, this boom has also affected the area of analytical chemistry. MNPs are now heavily utilized in many extraction procedures for the separation/pre-concentration of organic (Sajid et al., 2021; Wu et al., 2021) and inorganic (Filik and Avan, 2019; Er et al., 2020) analytes from environmental, biological, pharmaceutical, and food samples. However, the application of MNPs in column experiments is rather rare, probably due to their tendency to form agglomerates (Karadjova et al., 2016; Hashemi et al., 2018). In contrast, dispersive extraction techniques utilizing MNPs are reported more frequently, whether it is analytical research aimed at reliable quantification of different analytes present in aqueous samples (often at ultratrace concentration levels) or comparative studies on the removal of toxic pollutants from contaminated liquid matrices. The latter mainly involve thermodynamic and kinetic studies on the assessment of sorption capacity of the sorbents.

Our minireview summarizes the current knowledge on the latest trends in dispersive extraction, the so-called dispersive micro-solid phase extraction, where only a few units or tens of milligrams of nanosorbent are required. The focus is mainly on metal nanoparticles utilized for the separation and preconcentration of (ultra)trace inorganic analytes in DMSPE procedures. The examples of papers that have been published in recent years highlight the strong analytical potential of procedures that employ MNPs (either commercially available or synthesized in-house) and hybrid nanomaterials containing MNPs coupled with another (often carbon-based) nanomaterial.

Analyzing the data in Table 1, the following findings can be highlighted. Besides the desorption of the analyte carried out with an appropriate desorbing agent, which is the most common procedure performed in the last step of DMSPE before analyte quantification, other options had also been discussed. The first option involves dissolution of the nanosorbent material carrying adsorbed analyte and using the resulting solution for analysis (Krawczyk and Stanisz, 2015). Alternatively, a fine suspension of the sorbent containing adsorbed analyte may be prepared in the selected reagent and thus obtained "slurry" is then analyzed (Krawczyk and Stanisz, 2016). There are also studies in which no desorption procedure has been outlined. Instead, following extraction, the sorbent and the adsorbed analyte have been 
filtered off, dried and submitted for analysis along with the filter (Baranik et al., 2018a,b; Pytlakowska et al., 2020a,b). This type of procedure appears to be advantageous if the analyte is quantified by means of energy dispersive X-ray fluorescence spectrometry (EDXRF). The enrichment factor (EF) of 3350, which was calculated as a ratio of sensitivity of DMSPE-EDXRF procedure to sensitivity of the direct EDXRF measurement and reported by Pytlakowska et al. (2020a), can be considered abnormally high.

Similarly to other extraction techniques developed for preconcentration of the analyte of interest, the DMSPE approach allows for a several-fold reduction of the limits of detection (LODs). The lowest LODs were achieved with DMSPE-ICP-MS (Chen et al., 2020a,b). However, the LOD of $1.4 \mathrm{ng} / \mathrm{L}$ obtained when combining DMSPE and ICP-OES (at EF of 850) indicates that after optimization of the experimental conditions even a quantification method associated with significantly higher LODs can be reliably applied in ultratrace analysis. (In general, the LODs for ICP-OES based methods are very high compared to those obtained by ICP-MS and ETAAS. The LOD obtained by this method are broadly comparable with those reported for FAAS and application of this method for the direct determination of ultratrace concentrations of particular elements is rather rare.) The integration of DMSPE with HR-CS-ETAAS or CVAAS leads to further improvement with respect to LODs, the levels as low as $\mathrm{ng} / \mathrm{L}$ indicate that there is a great potential for the use of such arrangements in ultratrace analysis of inorganic analytes (Krawczyk and Stanisz, 2015, 2016; Stanisz and Krawczyk-Coda, 2017). The precision of the developed procedures [evaluated with relative standard deviation (RSD) values] has been found acceptable in all studies, although some works have reported RSD

\section{REFERENCES}

Baranik, A., Gagor, A., Queralt, I., Margui, E., Sitko, R., and Zawisza, B. (2018b). Determination and speciation of ultratrace arsenic and chromium species using aluminium oxide supported on graphene oxide. Talanta 185, 264-274. doi: 10.1016/j.talanta.2018.03.090

Baranik, A., Sitko, R., Gagor, A., and Zawisza, B. (2018a). Alumina/nano-graphite composite as a new nanosorbent for the selective adsorption, preconcentration, and determination of chromium in water samples by EDXRF. Anal. Bioanal. Chem. 410, 7793-7802. doi: 10.1007/s00216-018-1397-8

Chen, S. Z., Liu, Y. X., Wang, C. L., Yan, J. T., and Lu, D. B. (2020a). Determination of antimony speciation in cow milk using dispersive micro-solid phase extraction based on fibrous $\mathrm{TiO}_{2} @ g-\mathrm{C}_{3} \mathrm{~N}_{4}$ nanocomposites and ICP-MS after sample pretreatment by artificial gastric juice. Food Anal. Methods 13, 2102-2110. doi: 10.1007/s12161-020-01818-Z

Chen, S. Z., Liu, Y. X., Yan, J. T., Wang, C. L., and Lu, D. B. (2020b). Dispersive micro-solid phase extraction with fibrous $\mathrm{TiO}_{2} @ g-\mathrm{C}_{3} \mathrm{~N}_{4}$ nanocomposites coupled with ICP-MS for the determination of cobalt and nickel in environmental and biological samples. At. Spectrosc. 41, 169-174. doi: 10.46770/AS.2020.04.005

Chisvert, A., Cardenas, S., and Lucena, R. (2019). Dispersive microsolid phase extraction. TrAC Trends Anal. Chem. 112, 226-233. doi: 10.1016/j.trac.2018.12.005

Dastafkan, K., Khajeh, M., Ghaffari-Moghaddam, M., and Bohlooli, M. (2015). Silver nanoparticles for separation and preconcentration processes. $\operatorname{Tr} A C$ Trends Anal. Chem. 64, 118-126. doi: 10.1016/j.trac.2014.08.017

Er, E. O., Bozyigit, G. D., Buyukpinar, C., and Bakirdere, S. (2020). Magnetic nanoparticles based solid phase extraction methods for the determination of trace elements. Crit. Rev. Anal. Chem. doi: 10.1080/10408347.2020.1797465 above $10 \%$. In a recent study on UA-DMSPE extraction method coupled with CVAAS conducted by Krawczyk and Stanisz (2016), high RSDs (6-20\%) were observed for methylmercury in real water samples and biological material (Dogfish liver), which could be related to indirect detection approach for this analyte. RSDs for total $\mathrm{Hg}$ and $\mathrm{Hg}^{2+}$ measurements ranged from 4 to $11 \%$. Performing quantification of Ge in real plantbased food samples by UA-DMSPE-HR-CS-ETAAS, the highest RSD (23\%) was reported for white tea samples, where the analyte concentration was close to the detection limit (Stanisz and Krawczyk-Coda, 2017). In instances where the analyte concentration is below the quantification limit (LOQ), even RSD values around $20 \%$ are considered acceptable and the numerical value obtained for analyte concentration in the sample should be taken with some caution. The extraction yields reported in "recovery studies" indicate that monitored analytes were extracted quantitatively from different types of real samples.

If we realize that the amount of sorbent as low as $1 \mathrm{mg}$ added in tens of $\mathrm{mL}(25$ and $50 \mathrm{~mL}$ ) of sample is still sufficient to deliver reliable separation and pre-concentration of the target analyte even in the presence of a wide spectrum of possible interferents, it is hard to argue that the capabilities and achievements of these techniques have been anything other than remarkable.

\section{AUTHOR CONTRIBUTIONS}

IH and LN prepared the manuscript, made its revision, and final corrections. Both authors contributed to the article and approved the submitted version.

Filik, H., and Avan, A. A. (2019). Magnetic nanostructures for preconcentration, speciation, and determination of chromium ions: a review. Talanta 203, 168-177. doi: 10.1016/j.talanta.2019.05.061

Hagarová, I. (2020). Magnetic solid phase extraction as a promising technique for fast separation of metallic nanoparticles and their ionic species: a review of recent advances. J. Anal. Methods Chem. 2020:8847565. doi: 10.1155/2020/8847565

Hashemi, B., Zohrabi, P., and Shamsipur, M. (2018). Recent developments and applications of different sorbents for SPE and SPME from biological samples. Talanta 187, 337-347. doi: 10.1016/j.talanta.2018.05.053

Hassanpoor, S., Khayatian, G., and Azar, A. R. J. (2015). Ultra-trace determination of arsenic species in environmental waters, food, and biological samples using a modified aluminum oxide nanoparticle sorbent and AAS detection after multivariate optimization. Microchim. Acta 182, 1957-1965. doi: 10.1007/s00604-015-1532-6

Karadjova, I., Dakova, I., Yordanova, T., and Vasileva, P. (2016). Nanomaterials for elemental speciation. J. Anal. At. Spectrom. 31, 1949-1973. doi: 10.1039/C6JA00168H

Karlidag, N. E., Kocoglu, E. S., Toprak, M., Yilmaz, O., and Bakirdere, S. (2020b). Zirconium nanoparticles based dispersive solid phase extraction prior to slotted quartz tube-flame atomic absorption spectrophotometry for the determination of selenium in green tea samples. Food Chem. 329:127210. doi: 10.1016/j.foodchem.2020.127210

Karlidag, N. E., Toprak, M., Tekin, Z., and Bakirdere, S. (2020a). Zirconium nanoparticles based ligandless dispersive solid phase extraction for the determination of antimony in bergamot and mint tea samples by slotted quartz tube-flame atomic absorption spectrophotometry. J. Food Compos. Anal. 92:103583. doi: 10.1016/j.jfca.2020. 103583 
Khajeh, M., Laurent, S., and Dastafkan, K. (2013). Nanoadsorbents: classification, preparation, and applications (with emphasis on aqueous media). Chem. Rev. 113, 7728-7768. doi: 10.1021/cr400086v

Khan, S. B., Marwani, H. M., Asiri, A. M., and Bakhsh, E. M. (2016). Exploration of calcium doped zinc oxide nanoparticles as selective adsorbent for extraction of lead ion. Desalination Water Treat. 57, 19311-19320. doi: 10.1080/19443994.2015.1109560

Kiran, K. (2015). Gold nanoparticles for mercury determination in environmental water and vegetable samples. Appl. Nanosci. 5, 361-366. doi: $10.1007 / \mathrm{s} 13204-014-0325-2$

Krawczyk, M., and Stanisz, E. (2015). Silver nanoparticles as solid sorbent in ultrasound-assisted dispersive micro solid-phase extraction for the atomic absorption spectrometric determination of mercury in water samples. J. Anal. At. Spectrom. 30, 2353-2358. doi: 10.1039/C5JA00344J

Krawczyk, M., and Stanisz, E. (2016). Ultrasound-assisted dispersive micro solid-phase extraction with nano- $\mathrm{TiO}_{2}$ as adsorbent for the determination of mercury species. Talanta 161, 384-391. doi: 10.1016/j.talanta.2016. 08.071

Kumar, G. K., Sharma, P. S., Sounderajan, S., Datta, D., Singhal, R. K., and Udas, A. C. (2015). Optimization of the preconcentration of selenium IV on palladium nanoparticles (PdNPs), using multivariate analysis for the inorganic speciation of selenium in environmental water samples. Anal. Methods 7, 8262-8270. doi: $10.1039 /$ C5AY02023A

Li, Y. K., Yang, T., Chen, M. L., and Wang, J. H. (2020). Recent advances in nanomaterials for analysis of trace heavy metals. Crit. Rev. Anal. Chem. doi: 10.1080/10408347.2020.1736505. [Epub ahead of print].

Lin, Y. W., Huang, C. C., and Chang, H. T. (2011). Gold nanoparticle probes for the detection of mercury, lead, and copper ions. Analyst 136, 863-871. doi: 10.1039/C0AN00652A

Ma, T., Huang, Y., Yang, J. L., He, J. T., and Zhao, L. (2004). Preparation of spherical zirconia powder in microemulsion system and its densification behavior. Mater. Des. 25, 515-519. doi: 10.1016/j.matdes.2004.01.008

Marcano, D. C., Kosynkin, D. V., Berlin, J. M., Sinitskii, A., Sun, Z. Z., Slesarev, A., et al. (2010). Improved synthesis of graphene oxide. ACS Nano 4, 4806-4814. doi: $10.1021 / \mathrm{nn} 1006368$

Mohammadifar, E., Shemirani, F., Majidi, B., and Ezoddin, M. (2015). Application of modified nano-gamma-alumina as an efficient adsorbent for removing malachite green (MG) from aqueous solution. Desalination Water Treat. 54, 758-768. doi: 10.1080/19443994.2014.890549

Navrotskaya, A. G., Aleksandrova, D. D., Krivoshapkina, E. F., Sillanpaa, M., and Krivoshapkin, P. V. (2020). Hybrid materials based on carbon nanotubes and nanofibers for environmental applications. Front. Chem. 8:546. doi: $10.3389 /$ fchem.2020.00546

Nyaba, L., Matong, J. M., Dimpe, K. M., and Nomngongo, P. N. (2016). Speciation of inorganic selenium in environmental samples after suspended dispersive solid phase microextraction combined with inductively coupled plasma spectrometric determination. Talanta 159, 174-180. doi: 10.1016/j.talanta.2016.06.023

Omole, M., K’Owino, I., and Sadik, O. (2007). Palladium nanoparticles for catalytic reduction of $\mathrm{Cr}(\mathrm{VI})$ using formic acid. Appl. Catal. B 76, 158-167. doi: 10.1016/j.apcatb.2007.05.018

Pechishcheva, N. V., Shunyaev, K. Y., and Melchakova, O. V. (2018). Zirconium in modern analytical chemistry. Rev. Anal. Chem. 37:20170016. doi: $10.1515 /$ revac-2017-0016

Pyrzynska, K. (2020). Nanomaterials in speciation analysis of metals and metalloids. Talanta 212:120784. doi: 10.1016/j.talanta.2020.120784

Pytlakowska, K., Kocot, K., Hachula, B., Pilch, M., Wrzalik, R., and Zubko, M. (2020b). Determination of heavy metal ions by energy dispersive Xray fluorescence spectrometry using reduced graphene oxide decorated with molybdenum disulfide as solid adsorbent. Spectrochim. Acta Part B 167:105846. doi: $10.1016 /$ j.sab.2020.105846
Pytlakowska, K., Kocot, K., Pilch, M., and Zubko, M. (2020a). Ultrasoundassisted dispersive micro-solid phase extraction using molybdenum disulfide supported on reduced graphene oxide for energy dispersive X-ray fluorescence spectrometric determination of chromium species in water. Microchim. Acta 187:542. doi: 10.1007/s00604-020-04476-4

Sajid, M., Nazal, M. K., and Ihsanullah, I. (2021). Novel materials for dispersive (micro) solid-phase extraction of polycyclic aromatic hydrocarbons in environmental water samples: a review. Anal. Chim. Acta 1141, 246-262. doi: 10.1016/j.aca.2020.07.064

Sounderajan, S., Kumar, G. K., Kumar, S. A., Udas, A. C., and Venkateswaran, G. (2009). Characterization of As(V), As(III) by selective reduction/adsorption on palladium nanoparticles in environmental water samples. Talanta 78 , 1122-1128. doi: 10.1016/j.talanta.2009.01.027

Stanisz, E., and Krawczyk-Coda, M. (2017). ZnO nanoparticles as an adsorbent in ultrasound-assisted dispersive micro solid-phase extraction combined with high-resolution continuum source electrothermal atomic absorption spectrometry for determination of trace germanium in food samples. Microchem. J. 132, 136-142. doi: 10.1016/j.microc.2017.01.018

Sun, Y., Ha, W., Chen, J., Qi, H., and Shi, Y. (2016). Advances and applications of graphitic carbon nitride as sorbent in analytical chemistry for sample pretreatment: a review. TrAC Trends Anal. Chem. 84, 12-21. doi: $10.1016 / j . t r a c .2016 .03 .002$

Tekin, Z., Özdogan, N., and Bakirdere, S. (2020). Zirconium nanoparticles based solid phase extraction-slotted quartz tube-flame atomic absorption spectrophotometry for the determination of cadmium in wastewater samples and evaluation of green profile. Int. J. Environ. Anal. Chem. doi: 10.1080/03067319.2020.1728262. [Epub ahead of print].

Wu, A. M., Zhao, X. L., Wang, J. Y., Tang, Z., Zhao, T. H., Niu, L., et al. (2021). Application of solid-phase extraction based on magnetic nanoparticle adsorbents for the analysis of selected persistent organic pollutants in environmental water: a review of recent advances. Crit. Rev. Environ. Sci. Technol. 51, 44-112. doi: 10.1080/10643389.2020.1720493

Xu, F., Hu, J., Zhang, J., Hou, X. D., and Jiang, X. M. (2018). Nanomaterials in speciation analysis of mercury, arsenic, selenium, and chromium by analytical atomic/molecular spectrometry. Appl. Spectrosc. Rev. 53, 333-348. doi: 10.1080/05704928.2017.1323310

Yaqoob, S. B., Adnan, R., Rameez, K., Raja, M., and Rashid, M. (2020). Gold, silver, and palladium nanoparticles: a chemical tool for biomedical applications. Front. Chem. 8:376. doi: 10.3389/fchem.2020.00376

Yordanova, T., Vasileva, P., Karadjova, I., and Nihtianova, D. (2014). Submicron silica spheres decorated with silver nanoparticles as a new effective sorbent for inorganic mercury in surface waters. Analyst 139, 1532-1540. doi: 10.1039/c3an01279d

Zheng, F. Y., Li, S. X., Lin, L. X., and Cheng, L. Q. (2009). Simple and rapid spectrophotometric determination of trace titanium (IV) enriched by nanometer size zirconium dioxide in natural water. J. Hazard. Mater. 172, 618-622. doi: 10.1016/j.jhazmat.2009.07.042

Zhuang, Z., Yang, C., Wang, X., Yang, P., and Huang, B. (1996). Preconcentration of trace elements from natural water with palladium precipitation. J. Anal. Chem. 355, 277-280. doi: 10.1007/s0021663550277

Conflict of Interest: The authors declare that the research was conducted in the absence of any commercial or financial relationships that could be construed as a potential conflict of interest.

Copyright $\odot 2021$ Hagarová and Nemček. This is an open-access article distributed under the terms of the Creative Commons Attribution License (CC BY). The use, distribution or reproduction in other forums is permitted, provided the original author(s) and the copyright owner(s) are credited and that the original publication in this journal is cited, in accordance with accepted academic practice. No use, distribution or reproduction is permitted which does not comply with these terms. 